\title{
Isolated Bilateral Superior Rectii Paresis: A Rare Anomaly
}

\author{
Sana Nadeem \\ Department of Ophthalmology, Foundation University Medical College / Fauji Foundation Hospital, Rawalpindi, Pakistan
}

\begin{abstract}
We present a case of bilateral isolated superior rectus paresis in a 13-year girl who presented with alternating exotropia and hypertropia. She demonstrated bilateral paresis of elevation in abduction with an overaction of both the contralateral yoke muscles, i.e. inferior obliques. Neuroimaging did not reveal a lesion along the pathway of the third nerve nor hypoplasia of the superior rectus muscle. We performed a bilateral lateral rectus recession on adjustable sutures with bilateral myectomy of the inferior obliques (weakening of contralateral yoke muscle). At 1 year, the patient is well aligned and happy. Isolated extraocular muscle pareses are rare events, which present occasionally to the strabismus surgeons and need to be looked out for if the patient's strabismus looks peculiar. We believe we are the first to report an isolated paresis of the superior rectus muscle in Pakistan.
\end{abstract}

Key Words: Divergent strabismus, squint, paresis, hypertropia, exotropia, superior rectus muscle.

How to cite this article: Nadeem S. Isolated bilateral superior rectii paresis: A rare anomaly. J Coll Physicians Surg Pak 2019; 29(12):1218-1220.

\section{INTRODUCTION}

'Isolated paralysis' of the superior rectus was reported comprehensively for the first time in literature in 1933 by James White in his thesis, in which he included all cases with any degree of underaction of the muscle, which were classified from Group I to V. ${ }^{1}$ This rare phenomenon can be caused by an innervational abnormality in the course of the nerve supply from the nucleus to the insertion into the muscle; or muscle anomalies, abnormal insertion or absence.2,3 It may be congenital or acquired, the latter being caused by trauma, midbrain strokes 4,5 , myositis, vascular lesions, neoplasms, inflammations, or infections.6,7 Equal paresis of the superior rectii will result in equal hyperphoria, and with both eyes fixating, the deviation may be controlled; in dextroelevation, left hyperphoria will increase and in laevoelevation, right hyperphoria will increase. Treat-ment generally entails strengthening the paretic muscle, weakening the associated yoke muscle, or lessening the secondary contracture of the direct antagonist. We present a unique case of bilateral superior rectii paresis in a 13-year girl, which is the first instance to be reported in our country.

\section{CASE REPORT}

A 13-year girl presented with a peculiar strabismus, in the outpatient department of Fauji Foundation Hospital, Rawalpindi, which is a tertiary care teaching hospital. It was noted that she had an alternating exotropia and hypertropia and wanted to have surgery to correct her

Correspondence to: Dr. Sana Nadeem, Department of Ophthalmology, Foundation University Medical College /

Fauji Foundation Hospital, Jhelum Road, Rawalpindi, Pakistan

E-mail: sana.nadeem018@gmail.com

Received: January 08, 2019; Revised: March 28, 2019;

Accepted: April 06, 2019 deviation. Her uncorrected visual acuity was 6/6 bilaterally. Examination of anterior and posterior segments was normal. She was found to have defective elevation in abduction bilaterally, indicating paresis of both superior rectii ( -3 deficit of dextroelevation and laevoelevation in abduction) on extraocular motility testing, and an overaction of both the yoke muscles, i.e. inferior obliques (+3). Mild underaction of both superior obliques was noted as well. Diplopia was absent and this pointed to a congenital cause for her strabismus, which was confirmed by her parents.

Prism cover testing revealed an alternating exotropia of $45^{\triangle}$ with left dominance, with a left hypertropia of $10^{\Delta}$ in primary gaze at distance, with only an exotropia of $20^{\triangle}$ at near fixation. She had a 'V'-pattern of $35^{\Delta}$, an exotropia of $45^{\Delta}$ and left hypertropia of $12^{\Delta}$ in upgaze, exotropia of $10^{\triangle}$ and left hypertropia of $1^{\triangle}$ in downgaze, $25^{\triangle}$ exotropia and $20^{\triangle}$ left hypertropia in right gaze and $25^{\triangle}$ exotropia and $16^{\triangle}$ right hypertropia in left gaze (Figure 1). A head tilt was not noted.

Considering the possibility of bilateral superior rectii paresis, a thin section MRI of the orbit and brain contrast enhanced was ordered, which turned out to be normal (Figure 2). A general physical examination was normal and she did not have any comorbid conditions. Her baseline investigations were normal as well.

A bilateral lateral rectus recession of $8 \mathrm{~mm}$ was performed on a 'hang-back' suture with the fornix approach for surgery, and with the right eye on an adjustable suture, with a final adjustment to $5 \mathrm{~mm}$ OD; along with bilateral inferior oblique myectomies to weaken the overacting yoke muscles. A forced duction test at the time of surgery did not reveal any restrictive element. At 1-year follow-up, she is very happy and well aligned and the 'V'-pattern has resolved (Figure 3). 


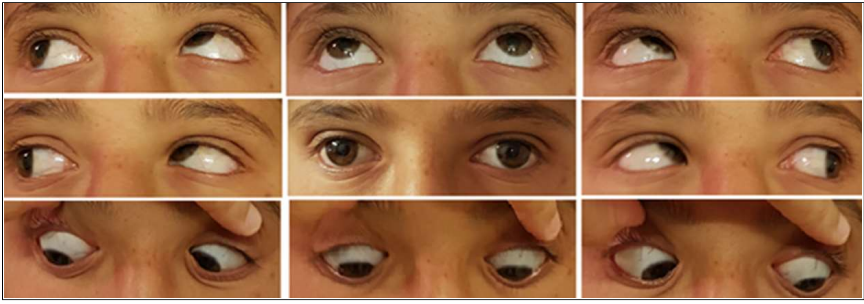

Figure 1: Bilateral superior rectus paresis, V-pattern exotropia and bilateral inferior oblique overaction.
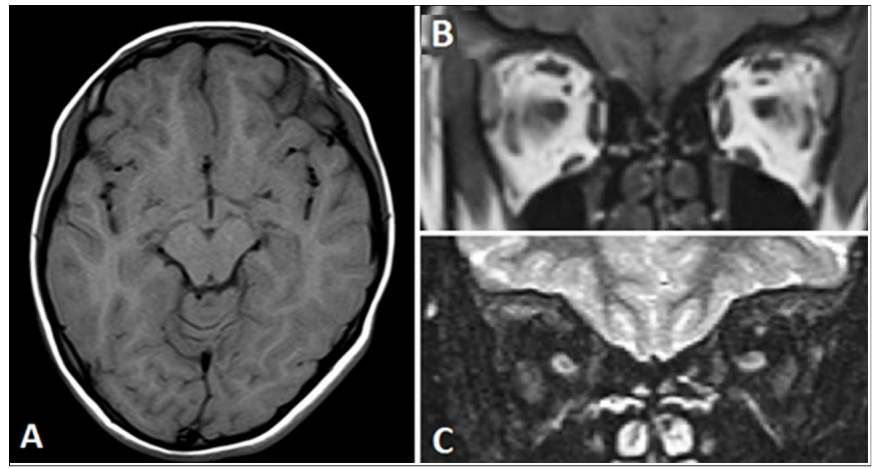

Figure 2: MRI of the orbit and brain. (A) Axial T1W MRI of the midbrain (B) Coronal T1W MRI of the orbit showing normal extraocular muscles.

(C) Coronal T2W normal MRI of the orbit post contrast.

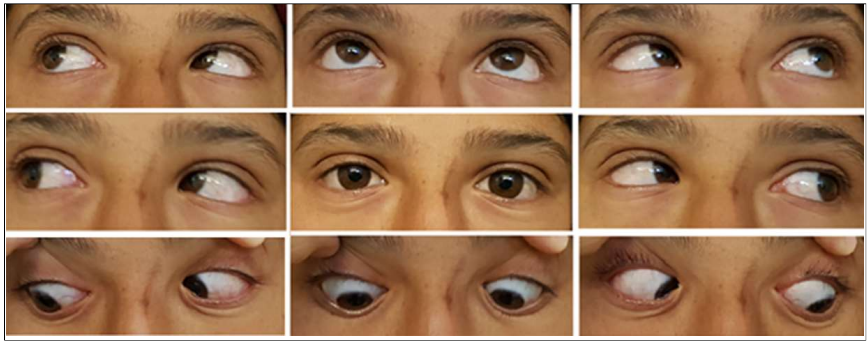

Figure 3: Postoperative appearance at 1 year.

\section{DISCUSSION}

The superior rectus muscle is the main elevator and an important master muscle of the eye. ${ }^{8}$ Its palsy can be due to structural, innervational or insertional etiologies. 1 It has a close embryological association with the levator, so that its paresis usually is accompanied by ptosis, due to both being supplied by the superior division of the oculomotor nerve. Pseudoptosis due to the ipsilateral hypotropia can also occur. In the instance of an isolated palsy of superior rectus, without ptosis, it can be due to the superior rectus muscles being hypoplastic, which can be confirmed by special neuroimaging techniques with thin sections. ${ }^{9,10}$ This case was a congenital paresis, and no cause was established even with neuroimaging. A classification of superior rectus paresis into 5 groups was done by White, in which he placed minimal underaction in Group I and total paralysis in Group V. ${ }^{1}$ It is important to differentiate a true palsy of the superior rectus muscle from an inhibitional palsy due to contralateral antagonist paralysis, i.e. superior oblique muscle. ${ }^{2}$ In our experience, the Parks-Bielchowsky three-step test is not much useful in bilateral cases of isolated extraocular muscle paralysis, and its utility remains controversial. 11 This case was a primary superior rectus paresis, although there was mild superior oblique underaction bilaterally, there was no contracture of superior rectus or any muscle, noted upon forced duction testing at the time of surgery. A V-pattern esotropia is more common in bilateral superior oblique palsy, compared to bilateral superior rectus palsy as in this case, there is a V-exotropia. ${ }^{12}$ In cases of equal bilateral paresis, a hypertropia will be absent when both eyes are fixating; but in this case, an unequal paresis of the superior rectii was present, characterised by a left hypertropia in the primary position, which disappeared upon near fixation. A head tilt is less common in superior rectus paresis, compared to superior oblique paralysis, as was our case. Diplopia occurs only in acquired cases, and in this congenital case, it was absent.

Treatment for paretic superior rectus is usually either a myotomy or myectomy of the yoke muscle (inferior oblique), which has been done in our case because the inferior oblique was overacting excessively and this has led to excellent results.1,6 Associated horizontal strabismus also needs to be treated for obtaining maximum cosmesis. Ipsilateral inferior rectus recession or myotomy can also be done, and superior rectus resection is another option, but paretic muscles rarely gain strength.

It is important to consider isolated paresis of the extraocular muscles as a cause while evaluating strabismus patients, for their better diagnosis and management.

\section{PATIENT'S CONSENT:}

The consents of the patient and parents were obtained for the publication of this case report.

\section{CONFLICT OF INTEREST:}

Authors declared no conflict of interest.

\section{AUTHOR'S CONTRIBUTION:}

SN: Concept and study design, drafting the manuscript, final approval of the verison to be published.

\section{REFERENCES}

1. White JW. Paralysis of the superior rectus muscle. Trans Am Ophthalmol Soc 1933; 21:551-84.

2. Adler FH. Physiologic factors in differential diagnosis of paralysis of superior rectus and superior oblique muscles. Arch Ophthalmol 1946; 36:661-73.

3. Mather TR, Saunders RA. Congenital absence of the superior rectus muscle: A case report. J Pediatr Ophthalmol Strabismus 1987; 24: 291-5.

4. Kwon JH, Kwon SU, Ahn HS, Sung KB, Kim JS. Isolated superior rectus palsy due to contralateral midbrain infarction. Arch Neurol 2003; 60:1633-5. 
5. Saito T, Asanome A, Sawada J, Katayama T, Hasebe N. A case of midbrain infarction causing ipsilateral mydriasis, contralateral superior rectus palsy, and bilateral ptosis. Neurol Sci 2013; 34:1683-4.

6. Lyle TK, Gross AG. Diagnosis and management of paralysis of the extrinsic ocular muscles with special reference to surgical treatment in 219 cases. Brit J Ophthalmol 1951; 35: 511-48.

7. Pollard ZF. Acute rectus muscle palsy in children as a result of orbital myositis. J Pediatr 1996; 128:230-3.

8. Jampolsky A. Superior rectus revisited. Trans Am Ophthalmol Soc 1981; 79:243-56.
9. Mims JL $3^{\text {rd }}$. Three similar but unique cases of isolated superior rectus extraocular muscle (EOM) palsy strabismus, presenting with large abnormal head tilts (postures, AHP). Binocul Vis Straboloq Q Simms Romano 2011; 26:154-69.

10. Demer JL, Clark RA, Kono R, Wright W, Velez F, Rosenbaum AL. A 12-year, prospective study of extraocular muscle imaging in complex strabismus. J AAPOS 2002; 6:337-47.

11. Kushner BJ. Errors in the three-step test in the diagnosis of vertical strabismus. Ophthalmology 1989; 96:127-32.

12. Von Noorden GK, Murray E, Wong SY. Superior oblique paralysis: A review of 270 cases. Arch Ophthalmol 1986; 104:1771-6. -......... 